\title{
Firefighter Nozzle Reaction
}

Chin, Selena K.; Sunderland, Peter B.; Jomaas, Grunde

\section{Published in:}

Fire Technology

Link to article, DOI:

10.1007/s10694-017-0661-3

Publication date:

2017

\section{Document Version}

Peer reviewed version

Link back to DTU Orbit

Citation (APA):

Chin, S. K., Sunderland, P. B., \& Jomaas, G. (2017). Firefighter Nozzle Reaction. Fire Technology, 53(5), 19071917. https://doi.org/10.1007/s10694-017-0661-3

\section{General rights}

Copyright and moral rights for the publications made accessible in the public portal are retained by the authors and/or other copyright owners and it is a condition of accessing publications that users recognise and abide by the legal requirements associated with these rights.

- Users may download and print one copy of any publication from the public portal for the purpose of private study or research.

- You may not further distribute the material or use it for any profit-making activity or commercial gain

- You may freely distribute the URL identifying the publication in the public portal

If you believe that this document breaches copyright please contact us providing details, and we will remove access to the work immediately and investigate your claim. 


\section{Firefighter Nozzle Reaction}

Selena K. Chin ${ }^{1}$, Grunde Jomaas ${ }^{2,3}$, Peter B. Sunderland ${ }^{1, *}$

${ }^{1}$ Department of Fire Protection Engineering, University of Maryland, College Park, MD, USA

${ }^{2}$ Department of Civil Engineering, Technical University of Denmark, Lyngby, Denmark

${ }^{3}$ BRE Centre for Fire Safety Engineering, University of Edinburgh, Edinburgh, United Kingdom

Submitted to: Fire Technology

Suggested reviewers: Vedha Nayagam, Michael Wieder

Type of article: Full-length article

Date: May 10, 2017

*Address correspondence to

Peter B. Sunderland

Associate Professor

University of Maryland

Dept. of Fire Protection Engineering

3104 J.M. Patterson Building

College Park MD 20742 USA

Tel: 001 (301) 405-3095

Fax: 001 (301) 405-9383

E-mail:pbs@umd.edu

Acknowledgments

Helpful discussions with W. Fletcher, H. Fowler, K. Isman, and E. Sluder, of UMD, are appreciated. S.K. Chin acknowledges support from the UMD RISE program. 


\title{
Firefighter Nozzle Reaction
}

\begin{abstract}
Nozzle reaction and hose tension are analyzed using conservation of fluid momentum and assuming steady, inviscid flow and a flexible hose in frictionless contact with the ground. An expression that is independent of the bend angle is derived for the hose tension. If this tension is exceeded owing to anchor forces, the hose becomes straight. The nozzle reaction is found to equal the jet momentum flow rate, and it does not change when an elbow connects the hose to the nozzle. A forward force must be exerted by a firefighter or another anchor that matches the forward force that the jet would exert on a perpendicular wall. Three reaction expressions are derived, allowing it to be determined in terms of hose diameter, jet diameter, flow rate, and static pressure upstream of the nozzle. The nozzle reaction predictions used by the fire service are $56-90 \%$ of those obtained here for typical firefighting hand lines. Sharing these findings with the fire protection community can improve the safety of firefighters.
\end{abstract}

Keywords: fluid mechanics; hose tension; hydraulics; kickback; spray

\section{Introduction}

Nozzle reaction (or kickback) is the force exerted on a firefighter or other anchor by a stationary spraying nozzle supplied by a flexible hose. The reaction direction is opposite that of the jet. Nozzle reaction can limit water delivery rate and increase firefighter air consumption rate, fatigue, and injuries [1-4]. Between 2007 and 2011 in the United States, an annual average of 13,795 firefighting injuries resulted from handling of charged hose lines, of which 3,565 were associated with overexertion [5]. Nozzle reactions have caused fatalities of pressure washer operators [6].

Hose tension is the longitudinal force supported by the walls of a flexible hose. The design and selection of hoses depends on reasonable estimates of hose tension.

Although many publications have analyzed firefighting nozzle reactions, none has considered the steady case of an anchored nozzle with an arbitrary hose bend angle, and none has addressed hose tension. The objective of this manuscript is to provide these analyses.

The fluid mechanics of nozzle reaction has attracted notable researchers including Mach, Prandtl, and Feynman [7-9]. Others showed that the reaction for a nozzle attached to a flexible hose via a $90^{\circ}$ elbow equals the jet momentum flow rate [10,11], a finding that also is obtained when the solution of Prandtl [8] is applied to a $90^{\circ}$ bend.

Nozzle reaction expressions are provided by the NFPA handbook and elsewhere $[1-4,12,13]$ and are widely used by the fire service. Unfortunately, no derivation or identification of the assumptions exists and recent publications have questioned these expressions [14,15]. This uncertainty may be increasing the reactions firefighters encounter and impeding the development of low-reaction nozzles [16].

A common problem considered in fluid mechanics textbooks is that of the tension between a spraying nozzle and a fixed metal pipe [17-19]. Several textbooks $[10,11,14,20,21]$ claim that the same solution applies when the pipe is replaced with a flexible hose. However, this problem has no steady solution because an unrestrained nozzle will flail around unsteadily. A firefighter or another anchor must push forward on the nozzle to prevent flailing.

Past work has noted that no general and correct solution for firefighting nozzle reaction exists $[15,22]$. For example, Albertson et al. [23] neglected the contribution of fluid momentum to hose tension and nozzle reaction, which is not valid for typical firefighting. Nazarenko [14] considered 
a case where an external force is applied to the hose far from the nozzle, but this has no steady solution and is different from firefighter practice. Recent work [14,15] questioned the direction of nozzle reactions when a hose is held perfectly straight, but this is impossible in practice.

The following analysis was undertaken to address the absence of a general solution for firefighter nozzle reaction. Simplifying assumptions (including steady inviscid flow, no gravity, and a flexible hose in frictionless contact with the ground) are made such that this analysis can proceed using elementary fluid mechanics. The resulting expressions are compared with the predictions in use by the fire service and with the limited available measurements.

\section{Hose Tension}

Hose tension is a parameter of interest to hose designers and users. It must be solved for before performing a control-volume analysis of firefighter nozzle reaction. To the authors' knowledge, no published solution exists for hose tension.

An analysis of tension in a bent hose is developed here assuming that the flow is (1) steady, (2) inviscid, and (3) incompressible laminar plug flow, with (4) no external longitudinal forces, such as gravity. Furthermore, the hose has (5) a constant inside diameter, is (6) flexible for bending but does not stretch circumferentially, and is (7) in frictionless contact with the ground.

For these assumptions, conservation of linear fluid momentum [17-21] can be expressed as

$$
\sum \overrightarrow{\mathbf{F}}_{\mathrm{cv}}=\int_{\mathrm{cs}} \overrightarrow{\mathbf{v}} \rho \overrightarrow{\mathbf{v}} \cdot \hat{\mathbf{n}} d A,
$$

where $A$ is the area, cs is the control surface, $\overrightarrow{\mathbf{F}}_{\mathrm{cv}}$ are all the external forces acting on the control volume, $\hat{\mathbf{n}}$ is the unit normal vector pointing outward, $\overrightarrow{\mathbf{v}}$ is the velocity, and $\rho$ is the fluid density.

Figure 1 shows a segment of a bent hose with fluid flowing from stations 1 to 2 . Its downstream end could be connected to another hose segment, a nozzle, a fixed pipe, or another plumbing component. The bend angle, $\theta$, can be any non-zero angle. As shown, the control volume is acted upon by four external forces. These are the inlet and outlet hose tensions, $\overrightarrow{\mathbf{T}}_{1}$ and $\overrightarrow{\mathrm{T}}_{2}$, and the pressure forces, $-p A_{1} \hat{\mathbf{n}}_{1}$ and $-p A_{1} \hat{\mathbf{n}}_{2}$, where $A_{1}$ is the cross-sectional area of the hose interior and $p$ is the gage static pressure. For the control volume of Fig. 1, Eq. (1) yields

$$
\overrightarrow{\mathbf{T}}_{1}+\overrightarrow{\mathbf{T}}_{2}-p A_{1}\left(\hat{\mathbf{n}}_{1}+\hat{\mathbf{n}}_{2}\right)=\rho A_{1}\left(\overrightarrow{\mathbf{v}}_{\mathbf{1}} \overrightarrow{\mathbf{v}}_{1} \cdot \hat{\mathbf{n}}_{1}+\overrightarrow{\mathbf{v}}_{\mathbf{2}} \overrightarrow{\mathbf{v}}_{2} \cdot \hat{\mathbf{n}}_{2}\right)
$$

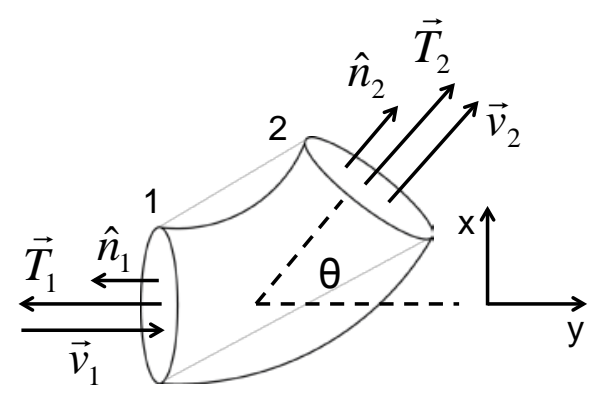

Figure 1. Hose segment control volume, which includes the hose and its contents. 
Separating Eq. (2) into its $x$ and $y$ components yields

$$
\begin{gathered}
-T_{1}+T_{2} \cos \theta+p A_{1}(1-\cos \theta)=\rho A_{1} v^{2}(\cos \theta-1) \text {, and } \\
\left(T_{2}-p A_{1}-\rho A_{1} v^{2}\right) \sin \theta=0,
\end{gathered}
$$

where $T_{1}$ and $T_{2}$ are the magnitudes of their associated vectors and $v$ is the scalar velocity. The $\sin \theta$ term in Eq. (4) cancels for any nonzero $\theta$. There is no unique solution when $\theta=0$, i.e., when the hose is perfectly straight. For any non-zero $\theta$, combining Eqs. (3) and (4) yields $T_{1}=T_{2}$, defined here as the scalar hose tension $T$, and

$$
T=p A_{1}+\rho Q^{2} / A_{1},
$$

where $Q$ is the volumetric flow rate.

According to Eq. (5), the bent hose tension is independent of the bend angle for any non-zero bend angle. In practice the hose tension cannot be reduced by holding the end of the hose perfectly straight $[14,15]$ because even an infinitesimal bend would yield the tension of Eq. (5). Hose tension is not higher for a $180^{\circ}$ bend than for a $90^{\circ}$ bend, as claimed by [15]. Although a bent hose tension lower than that of Eq. (5) is impossible, a higher hose tension will result if external forces pull the hose taught and straight.

In practice a streamwise pressure drop will cause a decreasing $T$ with distance. For a bent hose, the balance between $p$ and $T$ is such that the combined walls and contents are neither in tension nor compression.

\section{Nozzle Reaction}

Having solved for the hose tension, a control-volume analysis of the nozzle reaction is now possible. Assumptions (1) - (7) are again invoked such that the hose tension is given by Eq. (5). Additionally, it is assumed that (8) the jet consists of plug flow near the discharge, (9) the jet static pressure is atmospheric, and (10) the contraction coefficient [18] is unity.

Two configurations are considered, as depicted in Fig. 2. The standard configuration, Fig. 2a, involves a nozzle connected directly to a flexible hose. Figure $2 \mathrm{~b}$ includes an elbow with a bend angle, $\theta$, between the nozzle and the hose. This configuration is of interest because some manufacturers sell elbow-nozzle combinations $[24,25]$ and because a $90^{\circ}$ bend, as considered by several researchers $[10,11,26]$, can facilitate nozzle reaction experiments.

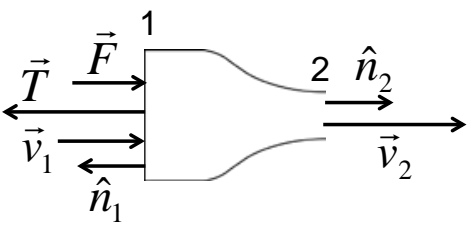

(a)

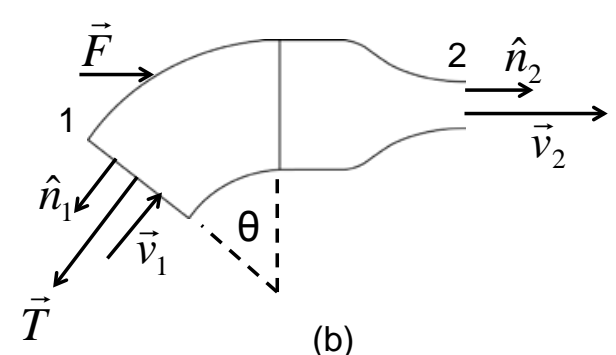

(b)

Figure 2. The control volumes for (a) a nozzle attached directly to a hose, and (b) a nozzle attached to a hose via an elbow. Both control volumes include the components shown and their contents. 
Separating the fire hose problem into the two control volumes of Fig. 1 and Fig. 2a or 2b is novel. Several past studies have combined these control volumes, e.g., [10,11,14], but this approach yields a single conservation of momentum equation with two unknown external forces: nozzle reaction and $T$. Consequently, no past study has arrived at a general solution for either hose tension or nozzle reaction.

For either control volume in Fig. 2, Eq. (1) yields:

$$
-p_{1} A_{1} \hat{\mathbf{n}}_{1}+\overrightarrow{\mathbf{T}}+\overrightarrow{\mathbf{F}}=\rho A_{1} \overrightarrow{\mathbf{v}}_{1} \overrightarrow{\mathbf{v}}_{1} \cdot \hat{\mathbf{n}}_{1}+\rho A_{2} \overrightarrow{\mathbf{v}}_{2} \overrightarrow{\mathbf{v}}_{2} \cdot \hat{\mathbf{n}}_{2},
$$

where $\overrightarrow{\mathbf{F}}$ is the anchor force vector, which is equal and opposite to the nozzle reaction, $\overrightarrow{\mathbf{R}}$.

Combining Eqs. (5) and (6) shows that, for both Figs. 2a and 2b, the direction of $\overrightarrow{\mathbf{R}}$ is opposite to the direction of the jet. In other words, a firefighter or other anchor must push on the nozzle in the direction of the jet and $\overrightarrow{\mathbf{R}}$ has no component perpendicular to the jet. For both Figs. 2a and 2b the magnitude of the nozzle reaction is

$$
R=\rho Q^{2} / A_{2} .
$$

According to Eq. (7), the reaction for a nozzle supplied by a bent hose is the jet momentum flow rate. Others obtained the same result for hoses [10,11] and metal pipes [26], but only considered bends of $90^{\circ}$. Equation (7) also appears in a nozzle catalog [25], but without attribution or explanation. No past study has derived Eq. (7) for an arbitrary bend angle or showed that $\overrightarrow{\mathbf{R}}$ has no component perpendicular to the jet.

Equation (7) counters the claim of Vera et al. [15] that the nozzle reaction is not the jet momentum flow rate. They supported this claim with experiments where a vertical hose was observed to stretch with increasing pressure and flow rate. However, this stretching is consistent with the increased hose tension, as expressed by Eq. (5). A forward external force was applied to the hose end by gravity acting on its heavy copper cladding.

A simple scenario yields an independent derivation of Eq. (7). Consider a pumper truck, a hose, and a spraying nozzle held by a firefighter. The hose is flexible, bent, and in frictionless contact with the ground such that it is anchored horizontally only at the pumper and at the firefighter's hands. The water jet impinges on a perpendicular vertical wall. External horizontal forces can act in three locations: where the pumper contacts the ground, at the firefighter's hands, and where the jet strikes the wall. In steady state, the sum of these forces is zero. Because the pumper's orientation cannot transmit down the hose, there can be no horizontal force where the pumper contacts the ground. The two other external forces must be equal and opposite. In other words, the firefighter's hands exert the forward force of Eq. (7) on the nozzle because the wall exerts a backward force of this magnitude on the jet.

Some manufacturers [24,25] suggest adding an elbow (see Fig. 2b) between the hose and the nozzle to reduce the nozzle reaction. Equation (7) shows this has no effect on the magnitude or direction of the reaction. In practice an elbow may allow friction between a stiff hose and the ground to support part of the nozzle reaction, but such effects are beyond the present scope.

The expression of Eq. (7) is plotted for representative conditions in Fig. 3, where the curves correspond to three jet diameters, $d_{2}$, defined according to

$$
A_{2}=\pi d_{2}^{2} / 4
$$


These diameters are representative of smooth bore nozzle sizes used by the fire service. The vertical lines in Fig. 3 correspond to NFPA requirements for the initial attack line and the backup line, 400 and $750 \mathrm{lpm}$, respectively [27]. The horizontal line shows the maximum reaction that a typical firefighter can handle alone, $334 \mathrm{~N}$ [2], although it is unknown how this was determined. Equation (7) shows that a firefighter working alone on a backup line can only be expected to deliver the required flow rate when the jet diameter exceeds $24.4 \mathrm{~mm}$.

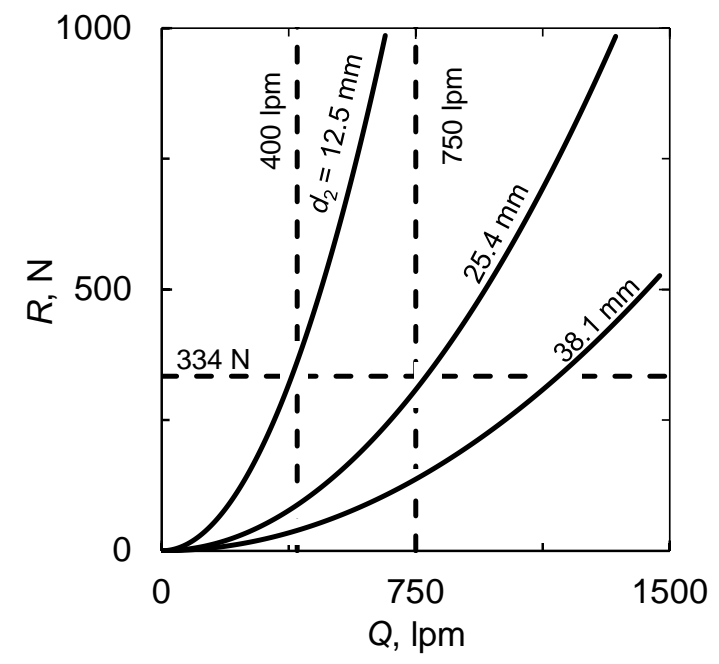

Figure 3. Dependence of the nozzle reaction, $R$, on the flow rate, $Q$, and the jet diameter.

In some cases the inputs to Eq. (7) are not known with sufficiency certainty, and an application of the Bernoulli equation between stations 1 and 2 in Figs. 2a and 2b becomes helpful. It is additionally assumed that (10) $A_{2}<A_{1}$ and (11) the discharge coefficient $[18,21]$ is unity. The Bernoulli equation yields

$$
p_{1}=\rho\left(v_{2}^{2}-v_{1}^{2}\right) / 2 .
$$

Combining Eqs. (7) and (9) yields

$$
R=\frac{2 A_{2} p_{1}}{1-\left(A_{2} / A_{1}\right)^{2}},
$$

which is convenient when $Q$ is unknown. Eqs. (7) and (9) can also be combined to obtain

$$
R=\left(2 \rho Q^{2} p_{1}+\rho^{2} Q^{4} / A_{1}^{2}\right)^{0.5},
$$

which is convenient when $A_{2}$ is unknown. In Eqs. (9) - (11) the appropriate $p_{1}$ is the gage static pressure where the hose connects to the nozzle, assuming there is no partially closed valve or other pressure loss downstream of this.

Obtaining a low reaction with a high flow rate requires a large $A_{2}$ (Eq. 7) and a low $p_{1}$ (Eq. 10). This will result in a low throw distance and increased hose kinking. Although $A_{1}$ appears in Eqs. (10) and (11), its effect is small for typical firefighting hand lines such as those considered below. 
Equations (7), (10) and (11) apply best to smooth-bore nozzles such as illustrated in Fig. 2. Reactions for fog and combination nozzles are approximated by Eq. (7) when jet divergence angle is small. Equations (10) and (11) do not apply to fog and combination nozzles with significant nozzle pressure losses. It has been suggested that fog and combination nozzles have the same reaction forces as solid streams [1-4], but Crapo [13] includes a correction for the jet divergence angle.

In the limit of $A_{2} / A_{1} \rightarrow 0$, Eqs. (10) and (11) reduce to these approximations:

$$
\begin{gathered}
R_{\text {approx }}=2 p_{1} A_{2} \text { and } \\
R_{\text {approx }}=Q\left(2 \rho p_{1}\right)^{0.5} .
\end{gathered}
$$

Other than differences in constants, Eqs. (12) and (13) match the widely used NFPA predictions of reaction forces $[1-4,12,13]$, for which the metric versions are

$$
\begin{aligned}
& R_{\mathrm{NFPA}}=0.0015 p_{1} d_{2}^{2} \text { and } \\
& R_{\mathrm{NFPA}}=0.0226 Q p_{1}{ }^{0.5}
\end{aligned}
$$

where $d_{2}$ is in mm, $Q$ is in lpm, $R_{\mathrm{NFPA}}$ is in $\mathrm{N}$, and $p_{1}$ is in $\mathrm{kPag}$.

It is informative to compare $R_{\mathrm{NFPA}}$ from Eq. (14) with $R$ from Eq. (10). The ratio $R_{\mathrm{NFPA}} / R$ depends only on the jet/hose diameter ratio, $d_{2} / d_{1}$, as shown in Fig. 4 . For $d_{2} / d_{1} \rightarrow 0, R_{\mathrm{NFPA}} / R$ $\rightarrow$ 0.95. Typical firefighting hand lines involve $d_{2} / d_{1}$ ratios of $0.5-0.8[1-4,12,13]$, for which $R_{\mathrm{NFPA}} / R$ is $0.56-0.90$. This could explain recommendations to augment the $R_{\text {NFPA }}$ predictions by a safety factor of $2-3$ [28].

Reactions encountered in practice may be lower than those predicted by Eqs. (7), (10), and (11). This is principally because a stiff hose combined with ground friction can support part of the reaction.

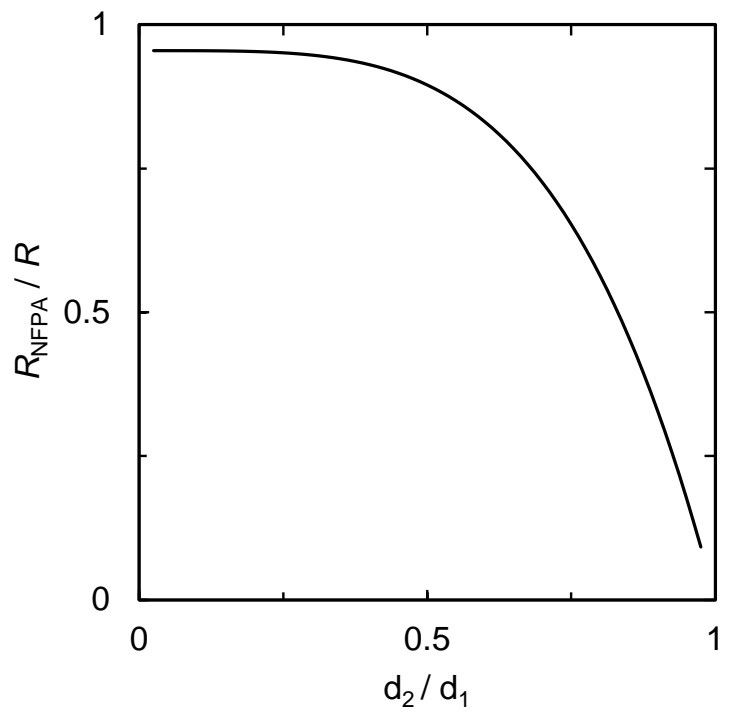

Figure 4. The reactions predicted by NFPA, Eq. (14), compared with the predictions of Eq. (10). 


\section{Measurements and Representative Predictions}

Unfortunately, there are no satisfactory published measurements of hose tension or nozzle reaction with which to validate the present analysis. Such tests are needed, but must be performed carefully to avoid the intrusion of hose stiffness, ground friction, gravity, etc.

Krishnakumar et al. [16] developed an advanced nozzle reaction measurement system. They measured 10 smooth-bore nozzle reactions, but they reported these only as pressure transducer readings and did not state the bore diameters. Their transducer readings did not approach zero without flow, indicating an experimental error. They attributed poor reproducibility to hose contact with the floor and walls, but gravity could also have interfered.

Nelson [29] measured 6 smooth-bore nozzle reactions, but provided no details of how the reactions were measured. The predictions of Eqs. (7), (10), and (11) exceed these measurements by an average factor of 1.67 . This difference is likely the result of hose stiffness and ground friction.

Vestal and Bridge [30] measured hose and nozzle performance (but not reactions) for two smooth-bore nozzles under typical firefighting conditions, see Table 1 . These facilitate estimates of hose tension and nozzle reaction encountered in practice. For both tests a pumper supplied a $44 \mathrm{~mm}$ diameter by $61 \mathrm{~m}$ long hose attached to the nozzle. The pumper pressure was adjusted to obtain the design $p_{1}$ of $345 \mathrm{kPag}$ just upstream of the nozzle. The highest hose tension is at the connection to the pumper.

All five expressions of nozzle reaction are tabulated in Table 1, and these are in reasonable agreement with one another. These reactions are generally within the $334 \mathrm{~N}$ capability of a typical firefighter [2]. For these cases, the $R_{\text {NFPA }}$ predictions are on average $9 \%$ lower than the predictions of Eqs. (10) and (11).

As Table 1 shows, Eqs. (7), (10), and (11) differ in practice. If there is a partially closed gate valve or other significant pressure loss between the nozzle pressure sensor and the discharge, only Eq. (7) is valid. For the conditions of Table 1, uncertainties in $Q$ have the largest effect on $R$; uncertainties in $A_{1}$ have the smallest effect; and for uncertainties of $10 \%$ in each of $A_{1}, A_{2}, Q$ and $p_{1}$, the uncertainties in $R$ for Eqs. (7), (10), and (11) are 23, 15, and 12\%, respectively. For all the smooth-bore conditions found in [29] and [30], Eq. (11) is between the other two, suggesting it is a good compromise in addition to having the lowest uncertainty.

\section{Table 1}

Predicted hose tensions and nozzle reactions for the two smooth-bore nozzle configurations of Vestal and Bridge [30].

\begin{tabular}{lccrr}
\hline Quantity & Eq. & Units & Test 1 & Test 2 \\
\hline$d_{2}$ & & $\mathrm{~mm}$ & 22 & 24 \\
$Q$ & & $\mathrm{lpm}$ & 568 & 681 \\
$p$ at pumper & & $\mathrm{kPa}$ & 793 & 965 \\
$p_{1}$ & & $\mathrm{kPag}$ & 345 & 345 \\
$T$ at pumper & 5 & $\mathrm{~N}$ & 1288 & 1580 \\
$T$ at nozzle & 5 & $\mathrm{~N}$ & 592 & 618 \\
$R$ based on $A_{2}$ and $Q$ & 7 & $\mathrm{~N}$ & 230 & 289 \\
$R$ based on $A_{1}, A_{2}$, and $p_{1}$ & 10 & $\mathrm{~N}$ & 285 & 335 \\
$R$ based on $A_{1}, Q$, and $p_{1}$ & 11 & $\mathrm{~N}$ & 255 & 309 \\
$R_{\text {NFPA }}$ based on $d_{2}$ and $p_{1}$ & 14 & $\mathrm{~N}$ & 255 & 293 \\
$R_{\text {NFPA }}$ based on $Q$ and $p_{1}$ & 15 & $\mathrm{~N}$ & 238 & 286 \\
\hline
\end{tabular}




\section{Conclusions}

An analysis of nozzle reaction and hose tension for firefighting was presented. The analysis was based on conservation of fluid momentum assuming steady inviscid flow and a flexible hose with frictionless ground contact. The major findings are as follows.

1. The tension in a bent hose is the pressure force plus the hose momentum flow rate, as expressed by Eq. (5). The hose tension is independent of the hose bend angle. If this tension is exceeded owing to anchor forces, the hose becomes straight.

2. The nozzle reaction equals the jet momentum flow rate. To avoid flailing this must be overcome with a force applied by a firefighter or other anchor in the direction of the jet.

3. Nozzle reaction can be predicted from Eq. (7), (10), or (11) depending on which geometric and flow quantities are known. The reaction direction and magnitude do not change when an elbow connects the hose to the nozzle.

4. For typical firefighting operations with smooth-bore nozzles, the reaction predictions used by the fire service are $56-90 \%$ of those obtained here.

5. The practical implications of this work are as follows. Low $R$ and high $Q$ requires high $A_{2}$ and low $\Delta p$. The hose diameter has a small effect on the reactions of typical firefighting lines.

Further studies that relax the assumptions invoked here would be of interest. Carefully conducted measurements of hose tension and nozzle reaction would be very helpful.

\section{References}

[1] Purington RG (1974) Fire fighting hydraulics. McGraw-Hill, New York, p 368

[2] Fornell DP (1991) Fire stream management handbook. PenWell, Saddle Brook, p 223

[3] Wieder MA (2005) Fire service hydraulics and water supply. Fire Protection Publications, Stillwater, p 248

[4] Wieder MA (2008) Fire streams, in Cote AE, Fire protection handbook. NFPA, Quincy, p 13-23

[5] Karter MJ (2013) Patterns of firefighter fireground injuries. NFPA, Quincy

[6] Rulseh TJ (2011) A fatality involving a waterjet nozzle provides a lesson in safety diligence when cleaning sewers. Cleaner Magazine, Nov., p 22

[7] Mach E (1919) The science of mechanics: a critical and historical account of its development. Open Court, Chicago, p 299

[8] Oertel H (2010) Prandtl - essentials of fluid mechanics. Springer, New York, p 93

[9] Feynman RP (1985) Surely you're joking, Mr. Feynman! Norton, New York, p 63-65

[10] Fay JM (1994) Introduction to fluid mechanics. MIT Press, Cambridge, p 194

[11] Lautrup B (2011) Physics of continuous matter. CRC, Boca Raton, p 357-358

[12] Theobald JJ (1946) Hydraulics for firemen, with problems and solutions. Barnes, New York, p 31

[13] Crapo WF (2017) Fire protection hydraulics and water supply. Jones and Bartlett, Burlington, p 151

[14] Nazarenko S (2015) Fluid dynamics via examples and solutions. CRC Press, Boca Raton, pp 20-35

[15] Vera F, Rivera R, Núñez C (2015) Letter to editor: Backward reaction force on a fire hose, myth or reality? Fire Technol 51:1023-1027

[16] Krishnakumar CK, Atallah S, Borows KA (1991) Development of a flow modifier for reducing the reaction force of firefighting nozzles. US Air Force Report ESL-TR-91-301 
[17] Alexandrou AN (2001) Principles of fluid mechanics. Pearson, p 126

[18] Shames IH (2003) Mechanics of fluids. McGraw-Hill, New York, p 195

[19] Crowe CT, Elger DF, Roberson JA (2005) Engineering Fluid Mechanics. Wiley, Hoboken NJ, p 194

[20] Graebel WP (2001) Engineering fluid mechanics. Taylor and Francis, New York p 155

[21] White FM (2016) Fluid mechanics. McGraw-Hill, New York, p 171

[22] Warren JW (1975) Forces on a hose. Phys Educ 10:327-328

[23] Albertson ML, Barton JR, Simons DB (1960) Fluid mechanics for engineers. Prentice-Hall, Englewood Cliffs, p 114

[24] AWG Fittings GmbH (2016) Fire and rescue catalog. http://www.awgfittings.com/fileadmin/catalogue/AWG/\#12. Accessed Jan. 24, 2017

[25] POK (2016) Firefighting equipment catalog. http://www.pok.fr/en/catalogues. Accessed Jan. 24, 2017

[26] Fang J (2011) Effect of nozzle design on reaction thrust and spray dynamics. M.S. Thesis, Univ. California, Davis

[27] NFPA 1410 (2015) Standard on training for initial emergency scene operations. NFPA, Quincy

[28] Sicking L (2002) How to calculate nozzle reaction. United States Forest Service. http://www.fs.fed.us/eng/pubs/html/02511318/02511318.htm. Accessed Jan. 24, 2017

[29] Nelson ME (2003) Vindicator nozzle and hose evaluation report. Montgomery County Maryland Fire and Rescue Service. http://www.1ststriketech.com/Testimonies/MontgomeryCountyReport.pdf. Accessed Jan. 24, 2017

[30] Vestal JN, Bridge EA (2010) A quantitative approach to selecting nozzle flow rate and stream, part 1. Fire Engin 163:10 